\title{
Les lois contre la prostitution : risque pour la santé et hypocrisie
}

L e droit canadien sur la prostitution a peu changé depuis que notre premier Code criminel a interdit les «maisons de débauche», le proxénétisme et le fait de vivre des fruits de la prostitution. À l'époque tout comme maintenant, le Code criminel n'interdisait pas l'achat et la vente de services sexuels. Ces lois de longue date contre la prostitution sont toutefois en grande partie inappliquées, comme s'en rendra compte quiconque consulte les pages jaunes à la rubrique «Services d'escorte». Il y a en fait longtemps que la plupart des municipalités ont baissé les bras pour se tourner plutôt vers la réglementation, la délivrance de permis et, comme dans le cas de tous les établissements commerciaux, la fiscalité. Comme citoyens, nous vivons tous des fruits de la prostitution.

Une loi plus récente est toutefois appliquée. En 1985, le gouvernement fédéral a mis en œuvre une nouvelle mesure anti-prostitution qui interdit de communiquer dans un endroit public pour acheter et vendre des services sexuels. Cette «disposition sur la communication» (qui met en évidence l'hypocrisie de nos lois sur la prostitution) voulait s'attaquer à la nuisance visible de la prostitution de rue - et certainement protéger la valeur des propriétés.

Outre le paradoxe juridique - il est légal d'acheter et de vendre des services sexuels, mais non de communiquer au sujet de la transaction - l'application de la loi favorise le client et met en danger les jeunes filles qui travaillent dans la rue. Lorsque des clients éventuels sont reconnus coupables de l'infraction criminelle qui consiste à «communiquer», il est rare qu'ils aillent en prison, contrairement aux prostituées ellesmêmes. Ils doivent se présenter à une «école de clients» non pas pour aborder la question d'une violation qui constitue une nuisance publique, mais plutôt pour assister à une «mise en scène morale sur la prostitution» d'une durée d'une journée'.

La mort prématurée constitue le grand risque que pose la prostitution pour la santé. Une récente étude américaine portant sur presque 2000 prostituées qu'on a suivies pendant 30 ans a révélé que les causes les plus fréquentes de mortalité étaient de loin l'homicide, le suicide, les problèmes reliés aux drogues et à l'alcool, l'infection par le VIH et les accidents dans cet ordre. Le taux d'homicide chez les prostituées actives était 17 fois plus élevé que dans la population féminine générale d'âge correspondant ${ }^{2}$.

Dans son analyse réfléchie et détaillée du droit canadien sur la prostitution ${ }^{1}$, John Lowman, de l'École de criminologie de l'Université Simon Fraser, décrit un commerce du sexe «à deux vitesses» au Canada : «Un commerce hors rue autorisé et un marché noir [dans la rue]». Des femmes (la plupart d'âge légal, soit de plus de 18 ans), dont la situation de vie est relativement stable, travaillent dans le commerce du sexe autorisé et réglementé hors rue dans une sécurité relative face au client abusif et sans être poursuivies par la police, tandis que de jeunes filles, souvent sans abri, doivent se battre dans la rue à la fois contre des clients et contre la police.

Elles mènent une vie précaire. Souvent âgées de moins de 18 ans, la plupart ont peu de compétences pour faire d'autre travail. Beaucoup d'entre elles, pour diverses raisons - pauvreté, maladie mentale, itinérance, violence pendant l'enfance - se tournent vers la prostitution comme seul moyen de survivre et de payer leurs nécessités de base. Lorsqu'elle ne les a pas poussées à quitter l'école et leur foyer, la toxicomanie fait souvent son apparition et rend encore plus minces leurs chances de dénicher un emploi plus sûr.

Visées par la police qui applique les lois sur la communication, les prostituées de rue doivent conclure trop rapidement leurs négociations avec leurs clients (souvent en montant dans le véhicule du client). Si elles sont ensuite victimes de violence ou de vol, elles signalent rarement l'incident à la police par crainte d'être poursuivies et emprisonnées. Les prostituées de rue sont en outre plus susceptibles de rencontrer des hommes qui recherchent la violence ou une combinaison de sexe et de violence. Ces hommes évitent les prostituées hors rue réglementées parce qu'il est habituellement très facile de les identifier au cours des négociations et du paiement des services sexuels. La plupart (80 \%) des prostituées assassinées en Colombie-Britannique entre 1975 et 1994 travaillaient dans la rue ${ }^{3}$.

Dans son rapport détaillé publié récemment, Prostitution de rue $e^{4}$, le Conseil permanent de la jeunesse du Québec exhorte la société à remplacer son hypocrisie morale par une stratégie de réduction des préjudices. Outre le vaste éventail de recommandations portant sur de grandes questions reliées à la prostitution de rue - pauvreté, scolarité, soins de santé, traitement contre les toxicomanies, police communautaire, etc. - le rapport recommande qu'on abroge les lois sur la communication qui visent à la fois les prostituées et leurs clients. Les médecins devraient exhorter les politiciens fédéraux à abroger toutes les lois sur la prostitution, comme le recommande Lowman, et à repartir à neuf. Les municipalités et les médecins spécialisés en hygiène publique et en soins communautaires doivent redoubler d'efforts pour protéger cette population vulnérable. - $7 A M C$

\section{Références}

1. Lowman J. Prostitution law reform in Canada [1997]. Disponible : http://mypage .uniserve.ca/ lowman/ProLaw/prolawcan.htm (consulté le 28 juin 2004).

2. Potterat JJ, Brewer DD, Muth SQ, Rothenberg RB, Woodhouse DE, Muth $\mathrm{JB}$, et al. Mortality in a long-term open cohort of prostitute women. Am 7 Epidemiol 2004;159:778-85.

3. Lowman J, Fraser L. Violence against persons who prostitute: the experience in British Columbia. Rapport technique TR1996-14e du ministère de la Justice du Canada, 1996.

4. Prostitution de rue : avis. Conseil permanent de la jeunesse, Gouvernement du Québec, avril 2004. 